\title{
Physico-chemical structure evolution characteristics of coal char during gasification in the presence of iron-based waste catalyst
}

\author{
Xinsha Zhang ${ }^{1} \cdot$ Xudong Song $^{1} \cdot$ Jiaofei Wang ${ }^{1} \cdot$ Weiguang Su ${ }^{1} \cdot$ Bing Zhou $^{2} \cdot$ \\ Yonghui Bai ${ }^{1}$ - Guangsuo $\mathrm{Yu}^{1,3}$
}

Received: 13 March 2020/Revised: 18 April 2020/Accepted: 25 July 2020/Published online: 7 August 2020

(C) The Author(s) 2020

\begin{abstract}
The present study aims to explore the physico-chemical structure evolution characteristic during Yangchangwan bituminous coal (YCW) gasification in the presence of iron-based waste catalyst (IWC). The catalytic gasification reactivity of YCW was measured by thermogravimetric analyzer. Scanning electron microscope-energy dispersive system, nitrogen adsorption analyzer and laser Raman spectroscopy were employed to analyze the char physico-chemical properties. The results show that the optimal IWC loading ratio was $5 \mathrm{wt} \%$ at $1000{ }^{\circ} \mathrm{C}$. The distribution of IWC on char was uneven and $\mathrm{Fe}$ catalyst concentrated on the surface of some chars. The specific surface area of YCW gasified semi-char decreased significantly with the increase of gasification time. i.e., the specific surface area reduced from $382 \mathrm{~m}^{2} / \mathrm{g}(0 \mathrm{~min})$ to $192 \mathrm{~m}^{2} / \mathrm{g}(3 \mathrm{~min})$, meanwhile, the number of micropores and mesopores decreased sharply at the late gasification stage. The carbon microcrystalline structure of YCW gasified semi-char was gradually destroyed with the increase of gasification time, and the microcrystalline structure with small size was gradually generated, resulting in the decreasing order degree of carbon microcrystalline structure. IWC can catalyze YCW gasification which could provide theoretical guidance for industrial solid waste recycling.
\end{abstract}

Keywords Char structure $\cdot$ Characteristic $\cdot$ Iron-based waste catalyst $\cdot$ Catalytic gasification

\section{Introduction}

The catalyst is the core of F-T synthesis technology. The iron-based waste catalyst (IWC) was discharged in the form of slag and wax. A large amount of IWC is treated by stacking, which not only results in a waste of resources, but also pollutes the ecological environment seriously. Coal gasification is considered as the cleanest form of coal

Yonghui Bai

yhbai@nxu.edu.cn

1 State Key Laboratory of High-efficiency Utilization of Coal and Green Chemical Engineering, Ningxia University, Yinchuan 750021, China

2 CHN Energy Ningxia Coal Industry Co., Ltd., Yinchuan 750000, China

3 Institute of Clean Coal Technology, East China University of Science and Technology, Shanghai 200237, China conversion (Zheng et al. 2019). If the recovered IWC could be applied to coal gasification, the gasification reactivity will be improved and the problem of industrial solid waste pollution for enterprises will be solved.

As we all know, the evolution characteristics of coal char structure will have a profound impact on catalytic gasification reactivity (Tay et al. 2014; Huo et al. 2014; Li et al. 2016; Wei et al. 2019; Liu et al. 2020). There are many reports on the characteristics of coal char structure during gasification in the presence of alkali metals and alkaline earth metals (Li et al. 2006; Liu et al. 2017a; Gao et al. 2017; Fan et al. 2019; Bai et al. 2019), but there are a few studies on the characteristics of coal char structure using iron-based catalysts, and most of the reports in the literature are carried out by using commercially available analytical reagents. Yu et al. (2006) selected $\mathrm{FeCl}_{3}$ as catalyst and used SEM to study the changes of $\mathrm{Fe}$ in the process of gasification. Zhang et al. (2015), Yu et al. (2019), Zhang et al. (2017) and Li et al. (2017) used SEM- 
EDS to characterize the distribution of catalyst on coal char surface during gasification. Xu et al. (2019) studied the characteristic of coal char structure and gasification reactivity under $\mathrm{Na}_{2} \mathrm{CO}_{3}, \mathrm{FeCO}_{3}$ and their composite catalysts and found that the coal char adsorption curve increased rapidly with $4 \mathrm{wt} \% \mathrm{FeCO}_{3}$. Qi et al. (2014) researched the effect of $\mathrm{Fe}\left(\mathrm{NO}_{3}\right)_{3}$ on structure characteristic and gasification reactivity of coal char and concluded that $\mathrm{Fe}$ increased the number of amorphous carbon structure. To sum up, at present, the effect of the coal char structure characteristics of loading iron-based catalyst on the gasification reactivity was reported based on analytical reagents, however, the systematic study on the physicochemical characteristics of coal char with loaded IWC is seldom reported.

In this work, Yangchangwan bituminous coal (YCW) was selected as feedstock for gasification in the presence of IWC. The catalytic gasification reactivity of YCW with loaded IWC was studied by TGA. And the physical and chemical structure properties of coal char with loaded IWC were systematically characterized by SEM-EDS, nitrogen adsorption analyzer and laser Raman spectroscopy, respectively. The aim is to deepen the understanding of the structure evolution mechanism of IWC as loading catalyst on the YCW char structure during gasification.

\section{Experimental}

\subsection{Samples preparation}

YCW was used as the raw material in this study. After crushing and sieving, the raw coal with particle size of 80-120 $\mu \mathrm{m}$ was selected to perform gasification. The proximate and ultimate analysis of raw coal was measured by Infra-Red Rapid Coal Analyzer (5E-MАСш) and elemental analyzer (Vario MACRO), respectively. The result

Table 1 Proximate and ultimate analyses of YCW

\begin{tabular}{lc}
\hline Analysis item & Content $(\mathrm{d}, \mathrm{wt} \%)$ \\
\hline$V M$ & 26.64 \\
$\mathrm{FC}$ & 56.81 \\
$\mathrm{Ash}$ & 16.55 \\
$\mathrm{C}$ & 64.42 \\
$\mathrm{H}$ & 3.63 \\
$\mathrm{~N}$ & 0.67 \\
$\mathrm{~S}$ & 1.14 \\
$\mathrm{O} *$ & 13.59 \\
\hline
\end{tabular}

Note: VM volatile matter; $F C$ fixed carbon; $d$ dry basis

*Calculated by difference is shown in Table 1. The ash composition of raw coal was analyzed by X-ray fluorescence spectrometer (Advant $\mathrm{XPX})$. The result is shown in Table 2 .

The IWC comes from CHN Energy Ningxia Coal Industry Co., Ltd. The alumina crucible loaded IWC was put in the muffle furnace, and then the temperature was heated up to $600{ }^{\circ} \mathrm{C}$, remaining for an hour to remove organic matter. The chemical analysis of IWC was carried out by X-ray fluorescence spectrometer (Advant XPX). The result is shown in Table 3 and the main chemical composition of IWC was $\mathrm{Fe}_{2} \mathrm{O}_{3}$.

\subsection{Char preparation}

The preparation of semi-char at different gasification time was carried out in a horizontal tube furnace. The schematic diagram of experimental device is shown in Fig. 1. Prior to the experiment, the dried IWC and YCW were ground by mortar and pestle with a ratio of $1: 19$, then about $2 \mathrm{~g}$ samples were evenly spread in an alumina crucible. At the beginning of gasification experiment, the flow rate of $100 \mathrm{~mL} / \mathrm{min} \mathrm{N}_{2}$ was introduced to the reactor so as to remove the air. After the temperature was heated up to $1000{ }^{\circ} \mathrm{C}$ at a heating rate of $20{ }^{\circ} \mathrm{C} / \mathrm{min}$ with $100 \mathrm{~mL} /$ $\min \mathrm{N}_{2}, \mathrm{~N}_{2}$ was cut off then, and the gasification agent $\mathrm{CO}_{2}$ was injected at the rate of $100 \mathrm{~mL} / \mathrm{min}$ into the reactor and held for different time (0,1, 1.5 and $3 \mathrm{~min}$, respectively). At the same time, the isothermal gasification was studied and semi-chars with different gasification time was produced.

\subsection{Gasification reactivity test}

The test of gasification reactivity was performed by TGA (NETZSCH STA449 F3, Germany). About $10 \mathrm{mg}$ samples were placed in alumina crucible, and heated to the target

Table 2 Ash chemical compositions of YCW

\begin{tabular}{lc}
\hline Component & Content (wt \%) \\
\hline $\mathrm{SiO}_{2}$ & 41.59 \\
$\mathrm{Al}_{2} \mathrm{O}_{3}$ & 18.28 \\
$\mathrm{Fe}_{2} \mathrm{O}_{3}$ & 9.27 \\
$\mathrm{CaO}$ & 12.25 \\
$\mathrm{Na}_{2} \mathrm{O}$ & 2.19 \\
$\mathrm{~K}_{2} \mathrm{O}$ & 1.51 \\
$\mathrm{MgO}$ & 4.77 \\
$\mathrm{SO}_{3}$ & 8.90 \\
$\mathrm{TiO}_{2}$ & 0.72 \\
$\mathrm{P}_{2} \mathrm{O}_{5}$ & 0.06 \\
$\mathrm{Other}$ & 0.46 \\
\hline
\end{tabular}


Table 3 Chemical analysis of IWC

\begin{tabular}{lc}
\hline Component & Content (wt\%) \\
\hline $\mathrm{SiO}_{2}$ & 32.35 \\
$\mathrm{Al}_{2} \mathrm{O}_{3}$ & 4.64 \\
$\mathrm{Fe}_{2} \mathrm{O}_{3}$ & 54.34 \\
$\mathrm{CaO}$ & 0.59 \\
$\mathrm{Na}_{2} \mathrm{O}$ & 0.36 \\
$\mathrm{~K}_{2} \mathrm{O}$ & 2.39 \\
$\mathrm{MgO}$ & 0.87 \\
$\mathrm{SO}_{3}$ & 0.32 \\
$\mathrm{TiO}_{2}$ & 0.06 \\
$\mathrm{P}_{2} \mathrm{O}_{5}$ & 0.03 \\
$\mathrm{Other}$ & 4.05 \\
\hline
\end{tabular}

gasification temperature at a heating rate of $20{ }^{\circ} \mathrm{C} / \mathrm{min}$ under $50 \mathrm{~mL} / \mathrm{min}$ air flow. Then, the atmosphere was switched to the gasification agent $\mathrm{CO}_{2}$ with a flow rate of $120 \mathrm{~mL} / \mathrm{min}$ for isothermal gasification in order to eliminate the effect of external diffusion on gasification (Zhang et al. 2019).

The carbon conversion $(X)$ and reactivity index $R_{0.9}(\mathrm{Gil}$ et al. 2015) of coal char were calculated by the Eqs. (1) and (2), respectively:

$X=\frac{w_{0}-w_{\mathrm{t}}}{w_{0}-w_{\infty}}$

$R_{0.9}=\frac{0.9}{t_{0.9}}$

In Eq. (1), $w_{0}, w_{\mathrm{t}}$ and $w_{\infty}$ represent the initial mass of the sample, the mass of the sample at the gasification time $t$ and the final mass of the sample at full gasification, respectively. In Eq. (2), $t_{0.9}$ refers to the gasification reaction time required when the conversion level of coal char reaches $90 \%$.

\subsection{Char structure characterization}

SEM (ZEISS EVO18, Germany) and EDS (BRUKER, Germany) were applied to analyze the surface morphology of coal char. At first, the sample holder covered with a little char was placed in an ion sputtering apparatus to goldplate. And then the processed samples were put into sample cell for measurement. The acceleration voltage was $15 \mathrm{kV}$.

The physical structure of coal char was characterized by JW-BK100C-01 nitrogen adsorption analyzer (Jingweigaobo, Beijing). The experiment was conducted at $-196{ }^{\circ} \mathrm{C}$. Before each test, all gasified semi-chars were degassed at $300{ }^{\circ} \mathrm{C}$ for $14 \mathrm{~h}$. BET and BJH models were used to calculate the specific surface area and the pore size distribution of coal char.

The chemical structure of coal char was analyzed by DXR laser Raman spectrometer (Thermo Fisher, US). The laser power was $2 \mathrm{~mW}$. The wavelength was $532 \mathrm{~nm}$ and the wave number was $800-2000 \mathrm{~cm}^{-1}$. The Origin 9.0 software was used to fit the original Raman spectrogram.

\section{Results and discussion}

\subsection{Coal char gasification reactivity}

Figure 2 shows the influence of different IWC loading ratios on YCW gasification reactivity. As seen in Fig. 2, at $900{ }^{\circ} \mathrm{C}$, the carbon conversion level of YCW coal char increased gradually with the increase of IWC loading ratio. When the IWC loading ratio increased from $0 \mathrm{wt} \%$ to $5 \mathrm{wt} \%$, the carbon conversion level increased significantly,

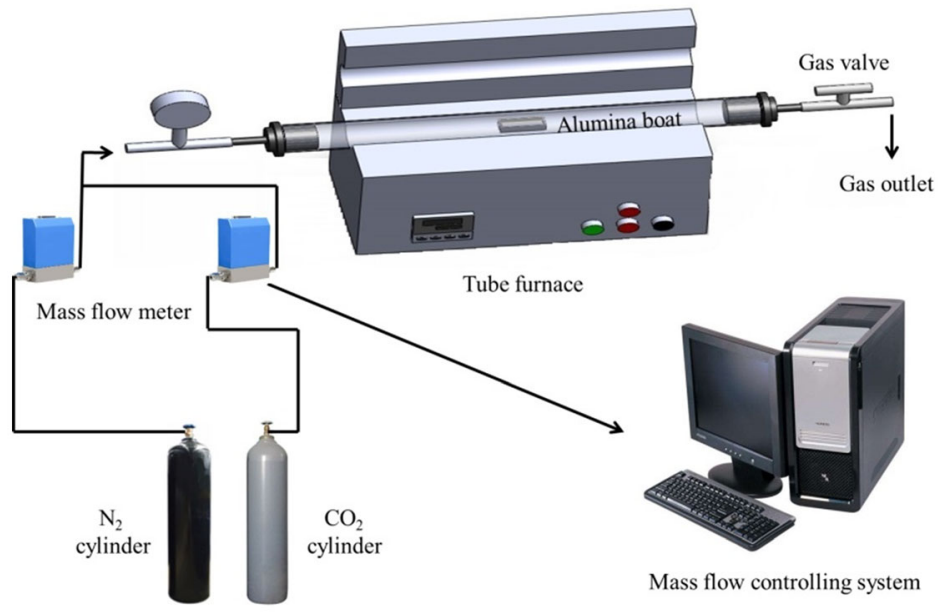

Fig. 1 Schematic diagram of tube furnace 


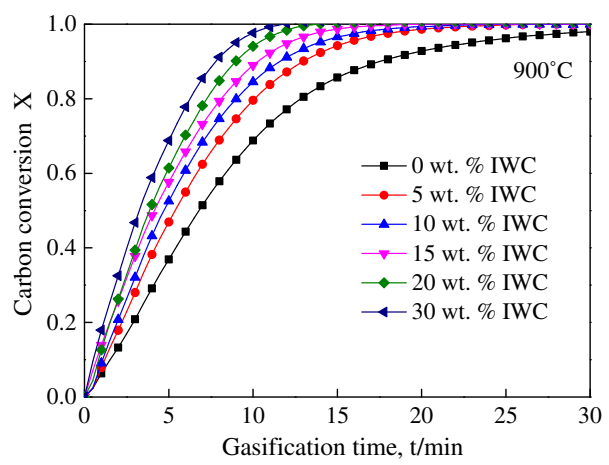

Fig. 2 YCW gasification reactivity under different IWC loading ratios

however, when the ratio rised from $5 \mathrm{wt} \%$ to $30 \mathrm{wt} \%$, the carbon conversion showed a low increase degree, not as obvious as previous.

In order to verify the effect of main metal oxide component $\left(\mathrm{Fe}_{2} \mathrm{O}_{3}\right)$ of IWC on YCW catalytic gasification, commercially available analytical reagent $\mathrm{Fe}_{2} \mathrm{O}_{3}$ catalyst was selected as the reference sample. The impact of IWC and analytical reagent $\mathrm{Fe}_{2} \mathrm{O}_{3}$ catalyst on $\mathrm{YCW}$ gasification reactivity were analyzed by TGA. Figure 3 shows the comparative analysis results of the influence of two catalysts on YCW gasification reactivity at $1000{ }^{\circ} \mathrm{C}$. Obviously, the difference between carbon conversion curve of $5 \mathrm{wt} \%$ IWC and $\mathrm{Fe}_{2} \mathrm{O}_{3}$ loaded on YCW is very small and the difference of $R_{0.9}$ is 0.01 . This indicates that the gasification reactivity of $\mathrm{YCW}$ with IWC and $\mathrm{Fe}_{2} \mathrm{O}_{3}$ loaded has a little difference. And as can be seen from the chemical composition analysis of IWC in Table 3, the metal oxide of catalyzing YCW gasification is $\mathrm{Fe}_{2} \mathrm{O}_{3}$ in IWC.

In order to further investigate the influence of IWC loading ratio on gasification reactivity at high temperatures, the effect of different loading ratios on YCW gasification reactivity was investigated at $1000{ }^{\circ} \mathrm{C}$. The result is shown in Fig. 4. There is little difference between the

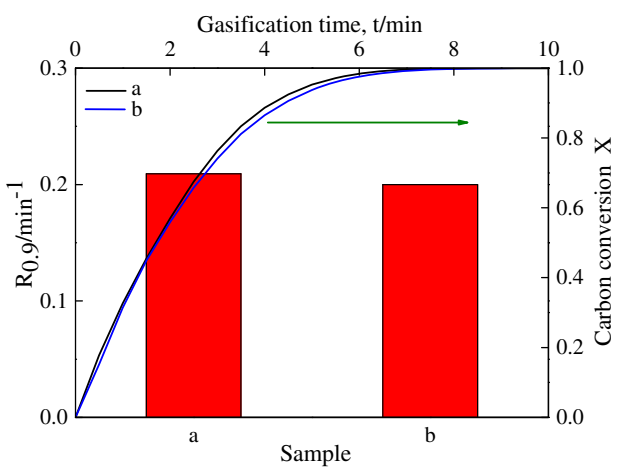

Fig. 3 IWC and analytical reagent $\mathrm{Fe}_{2} \mathrm{O}_{3}$ catalyst on YCW gasification reactivity at $1000{ }^{\circ} \mathrm{C} . \quad(a) \mathrm{YCW}+5 \mathrm{wt} \%$ IWC; b $\mathrm{YCW}+5$ wt $\%$ analytical reagent $\mathrm{Fe}_{2} \mathrm{O}_{3}$ )

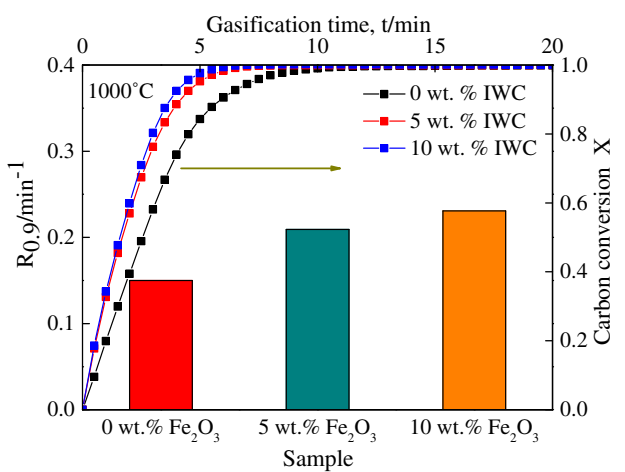

Fig. 4 Different IWC loading ratio on YCW gasification reactivity at $1000{ }^{\circ} \mathrm{C}$

carbon conversion curves of YCW with $5 \mathrm{wt} \%$ and $10 \mathrm{wt} \%$ IWC loaded. The difference of $R_{0.9}$ value between them was 0.02 . This indicates that when IWC loading ratio reached $10 \mathrm{wt} \%$, the impact of loading ratio on $\mathrm{YCW}$ catalytic gasification reaction was slight. Thus, the optimal loading ratio of IWC was $5 \mathrm{wt} \%$.

\subsection{Char physical structure evolution}

The surface morphology and $\mathrm{Fe}$ catalyst distribution of semi-char from YCW gasification with $5 \mathrm{wt} \%$ IWC loaded at $1000{ }^{\circ} \mathrm{C}$ is shown in Fig. 5. Apparently, the surface of YCW char with different gasification time is rough and the distribution of Fe catalyst on coal char particle is not uniform, mainly concentrated on some coal char particles. In Fig. 5b, there are many small pits on the coal char particle surface, and the distribution of $\mathrm{Fe}$ catalyst on coal char particle is more uniform than that of $0 \mathrm{~min}$. In Fig. $5 \mathrm{c}$, the agglomeration of $\mathrm{Fe}$ catalyst on coal char particle is observed. It can be seen from Fig. 5d that Fe catalyst has entered into the interior pore.

Table 4 shows the specific surface area of YCW gasified semi-char with $5 \mathrm{wt} \%$ IWC loaded at $1000{ }^{\circ} \mathrm{C}$. The results show that the specific surface area of semi-char gradually decreases with the increase of time. The order of specific surface area of semi-char is (YCW $+5 \mathrm{wt} \%$ IWC)$1000{ }^{\circ} \mathrm{C}-0 \mathrm{~min}>(\mathrm{YCW}+5 \mathrm{wt} \% \quad$ IWC $)-1000{ }^{\circ} \mathrm{C}-$ $1 \mathrm{~min}>(\mathrm{YCW}+5 \mathrm{wt} \% \quad \mathrm{IWC})-1000{ }^{\circ} \mathrm{C}-1.5 \mathrm{~min}>($ $\mathrm{YCW}+5 \mathrm{wt} \%$ IWC)-1000 ${ }^{\circ} \mathrm{C}-3 \mathrm{~min}$ and the specific surface area of (YCW $+5 \mathrm{wt} \%$ IWC)- $1000{ }^{\circ} \mathrm{C}-0$ min is 1.99 times higher than that of (YCW $+5 \mathrm{wt} \%$ IWC)$1000{ }^{\circ} \mathrm{C}-3 \mathrm{~min}$. This indicates that the specific surface area of semi-char gradually decreases during gasification. For a phenomenon like this, Ding et al. (2015), Chang et al. (2020) also conducted similar studies and found that the specific surface area gradually decreased with the increase of gasification time because the generated ash blocked the pore structure. 

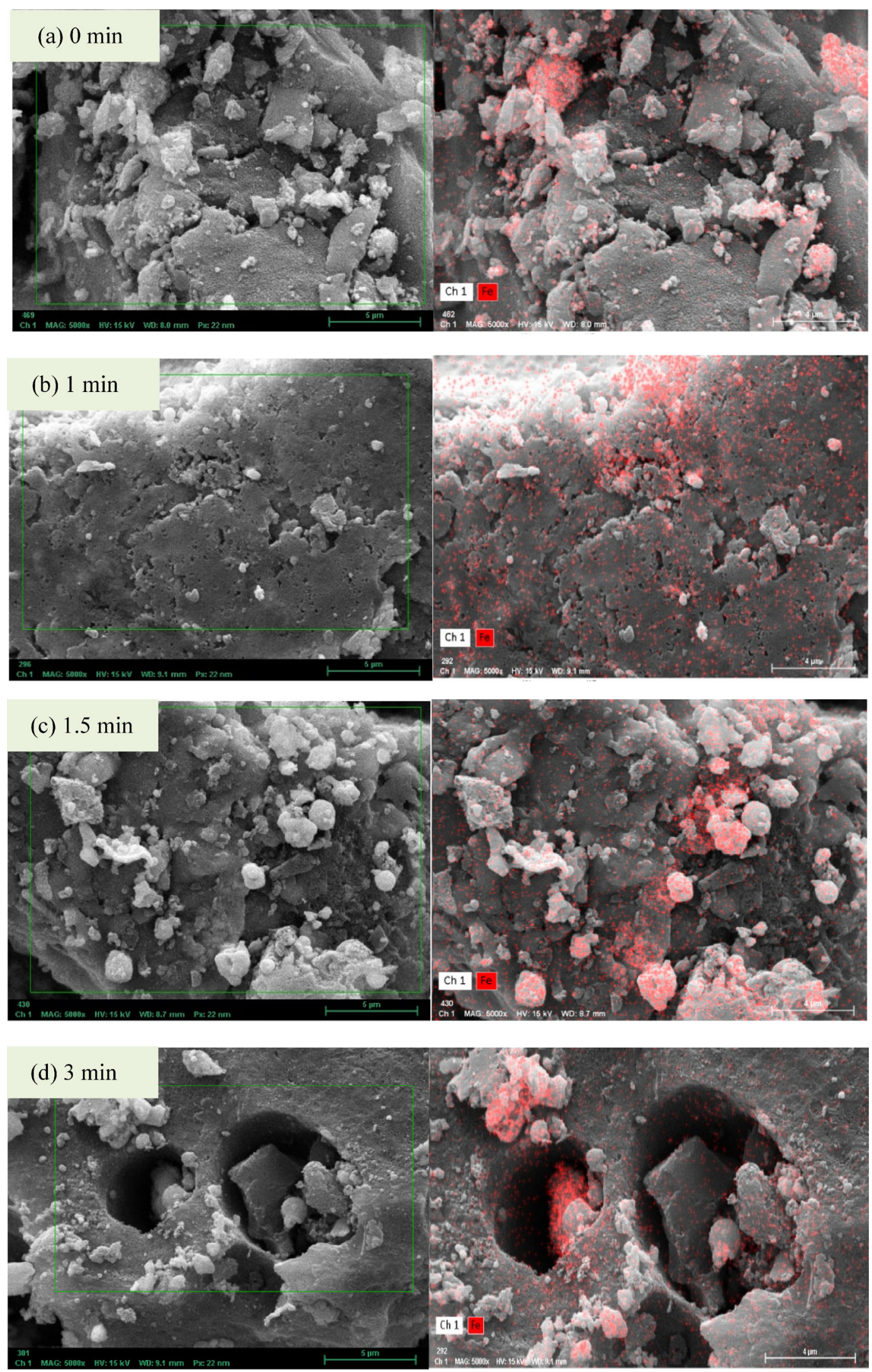

Fig. 5 Surface morphology and Fe catalyst distribution of semi-char from YCW gasification with 5 wt $\%$ IWC loaded at $1000{ }^{\circ} \mathrm{C}$ 
Table 4 Specific surface area of different gasified semi-chars

\begin{tabular}{ll}
\hline Sample & $S_{\mathrm{BET}}\left(\mathrm{m}^{2} / \mathrm{g}\right)$ \\
\hline$(\mathrm{YCW}+5 \mathrm{wt} \% \mathrm{IWC})-1000{ }^{\circ} \mathrm{C}-0 \mathrm{~min}$ & 382 \\
$\left(\mathrm{YCW}+5 \mathrm{wt} \%\right.$ IWC)-1000 ${ }^{\circ} \mathrm{C}-1 \mathrm{~min}$ & 324 \\
$(\mathrm{YCW}+5 \mathrm{wt} \% \mathrm{IWC})-1000{ }^{\circ} \mathrm{C}-1.5 \mathrm{~min}$ & 292 \\
$(\mathrm{YCW}+5 \mathrm{wt} \% \mathrm{IWC})-1000{ }^{\circ} \mathrm{C}-3 \mathrm{~min}$ & 192
\end{tabular}

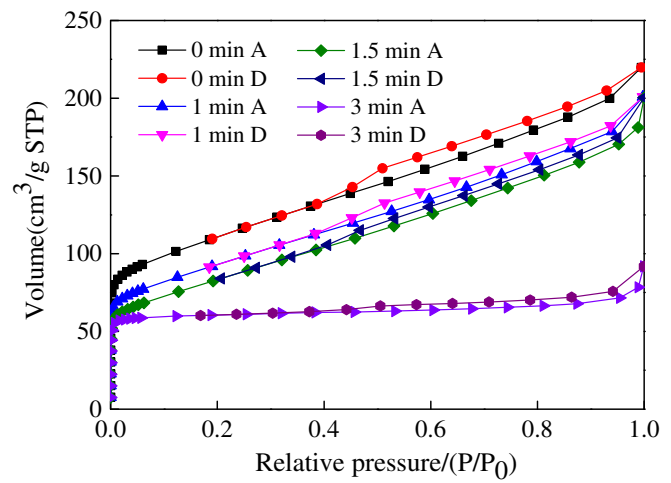

(a) $\mathrm{N}_{2}$ adsorption/desorption isotherms

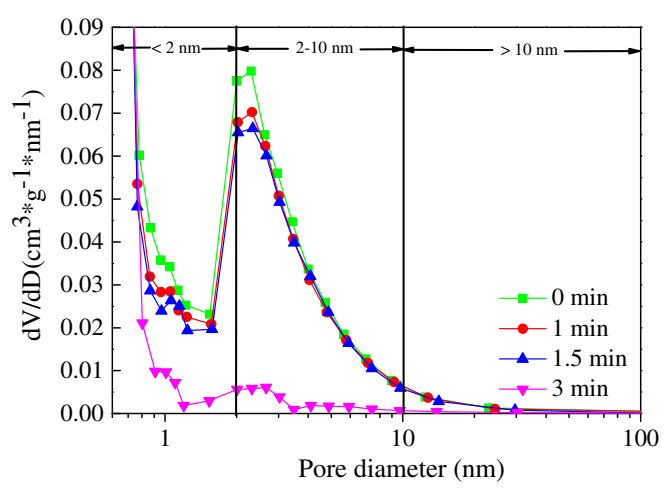

(b) pore size distribution

Fig. 6 Nitrogen adsorption/desorption isotherms and pore size distribution of YCW gasified semi-chars with $5 \mathrm{wt} \%$ IWC loaded at $1000{ }^{\circ} \mathrm{C}$ (A: adsorption isotherm; D: Desorption isotherm)

Figure 6 presents the nitrogen adsorption/desorption isotherms and pore size distribution of semi-char from YCW gasification with $5 \mathrm{wt} \%$ IWC loaded at $1000{ }^{\circ} \mathrm{C}$. Figure 6 a shows that the gas adsorption capacity increases rapidly in the region of low relative pressure, which is attributed to the filling of micropore. The adsorption volume increases continuously with the increase of relative pressure, and this is due to multilayer adsorption in the pore. In addition, the nitrogen adsorption/desorption isotherm also shows that the desorption volume is significantly larger than the adsorption volume. When $P / P_{0}$ exceeds to 0.4 , hysteresis loops appear, indicating that there are mesopores in different gasification semi-chars.

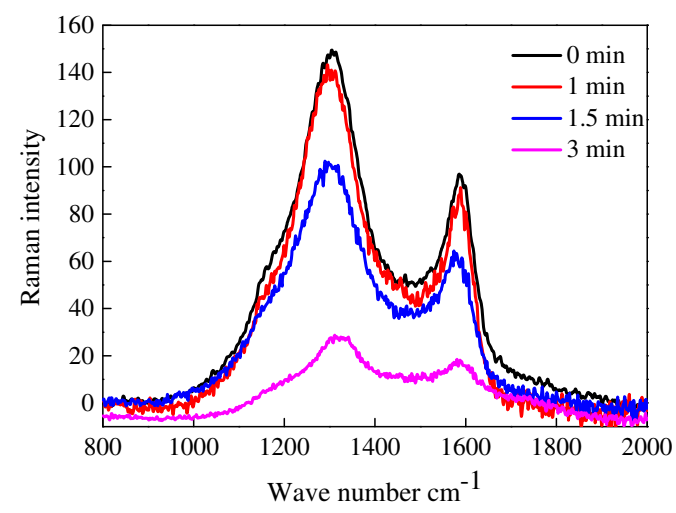

Fig. 7 Original Raman spectrogram of YCW semi-chars with $5 \mathrm{wt} \%$ IWC loaded at $1000{ }^{\circ} \mathrm{C}$

According to the analysis of nitrogen adsorption/desorption isotherm in Fig. 6a, YCW gasified semi-char loaded with $5 \mathrm{wt} \%$ IWC has a continuous pore structure. The specific pore size distribution result is shown in Fig. 6b. It can be seen that the pore structure of different $\mathrm{YCW}$ gasified semi-chars is mainly composed of micropore less than $2 \mathrm{~nm}$ and mesopore between $2-10 \mathrm{~nm}$. The number of micropores and mesopores are essentially unchanged at $1 \mathrm{~min}$ and $1.5 \mathrm{~min}$, however, their number decreases sharply at $3 \mathrm{~min}$. This is also consistent with the specific surface area analysis results in Table 4 . For such a phenomenon, $\mathrm{Li}$ et al. (2019) found that the reduction of specific surface area was caused by the melting and sintering of pores in the gasification process.

\subsection{Char chemical structure evolution}

The effect of IWC on char chemical structure was analyzed by Raman spectroscopy. Figure 7 shows the original Raman spectra of YCW gasified semi-char with $5 \mathrm{wt} \%$ IWC loaded at $1000{ }^{\circ} \mathrm{C}$. The results show that each original Raman spectrum has a D band at about $1350 \mathrm{~cm}^{-1}$ and a G band approximately at $1580 \mathrm{~cm}^{-1}$. The $\mathrm{D}$ band represents the carbon structure with a defective structure in coal char, and it mainly represents the $\mathrm{C}-\mathrm{C}$ bonds between the larger aromatic ring (not less than 6 fused rings) and the fused ring in the coal char. The $\mathrm{G}$ band is considered as graphite peak.

External factors have a great influence on the peak intensity and other information of the original spectrum, and because the $\mathrm{D}$ and $\mathrm{G}$ band overlaps, using only the $\mathrm{D}$ band and $\mathrm{G}$ band of the original Raman spectrum leads to the loss or neglect of the characteristic information of highly disordered carbonaceous materials ( $\mathrm{Li}$ et al. 2006). Hence, the quantitative correlation between Raman spectra and structural parameters cannot be realized. It is necessary 


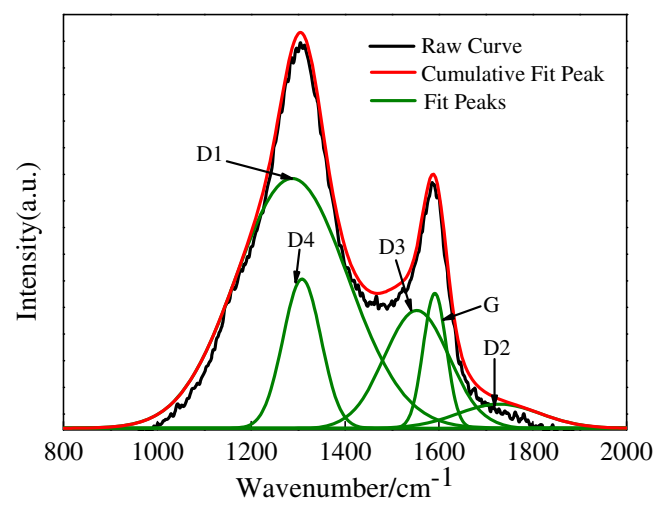

Fig. 8 Curve-fitted Raman spectrum of YCW semi-char with 5 wt $\%$ IWC loaded at $1000{ }^{\circ} \mathrm{C}$

to further fit the original Raman spectra of coal char and obtain the hidden information of skeleton carbon structure in the overlapping region. In order to get more information about the structural change of coal char in the process of gasification reaction, it is essential to carry out fractional peak fitting on the original spectrum (Sheng 2007; Smith et al. 2016). The Origin 9.0 software is used to perform peak fitting on the original Raman spectrogram in this study. According to the chemical structure characteristics of coal char (Mosqueda et al. 2019; Wei et al. 2018), the original Raman spectrum was fitted into five bands, namely Lorenzian bands (G, D1, D2 and D4) and Gaussian band (D3). Figure 8 shows the peak fitting diagram of Raman spectra of semi-char from YCW gasification with $5 \mathrm{wt} \%$ IWC loaded at $1000{ }^{\circ} \mathrm{C}$. The D1 band is about $1350 \mathrm{~cm}^{-1}$ and usually refers to as the defect peak, mainly the plane defect of the carbon structure. The peak position of D2 is around $1620 \mathrm{~cm}^{-1}$, which usually appears as the acromion of $\mathrm{G}$ band, mainly as disordered graphite lattice. The D3 band is located near $1500 \mathrm{~cm}^{-1}$ and represents $\mathrm{sp}^{2}$ hybrid amorphous carbon structure, including small organic molecules and fragmented functional groups. The attribution of the D4 band is still controversial, and its peak is usually around $1200 \mathrm{~cm}^{-1}$, but it is generally to be considered as the $\mathrm{sp}^{2}-\mathrm{sp}^{3}$ hybrid bond consisting of $\mathrm{C}-\mathrm{C}$ and $\mathrm{C}=\mathrm{C}$ stretching vibrations.

The integral area ratio of peak is often used as a parameter to characterize the chemical structure of coal char. $I_{\mathrm{D} 1} / I_{\mathrm{G}}$ is often used to quantitatively analyze the order degree of carbon structure. Namely, the higher the $I_{\mathrm{D} 1} / I_{\mathrm{G}}$ ratio, the lower the order degree of carbon structure. Figure 9 shows the relationship between $I_{\mathrm{D} 1} / I_{\mathrm{G}}$ and catalytic reactivity of different semi-chars from $\mathrm{YCW}$ gasification with $5 \mathrm{wt} \%$ IWC loaded at $1000{ }^{\circ} \mathrm{C}$. It can be seen that the integral area ratio of $I_{\mathrm{D} 1} / I_{\mathrm{G}}$ increases with the increase of gasification time. This indicates that the carbon

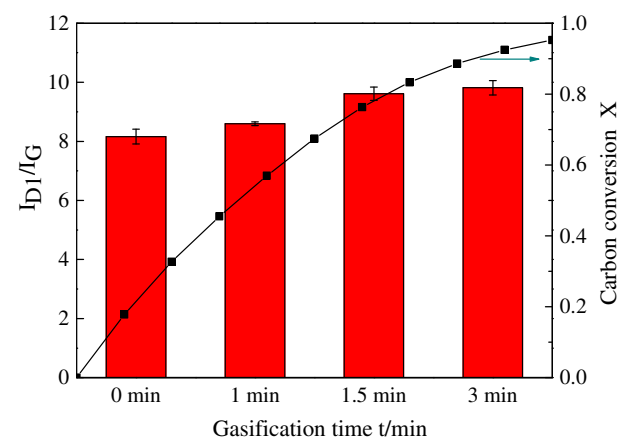

Fig. 9 Relationship between $I_{\mathrm{D} 1} / I_{\mathrm{G}}$ and catalytic reactivity of different YCW semi-chars with $5 \mathrm{wt} \%$ IWC loaded at $1000{ }^{\circ} \mathrm{C}$

microcrystalline structure is gradually destroyed and the microcrystalline structure of small size was gradually generated. Therefore, the order degree of carbon structure decreased at high carbon conversion level. At the same time, as seen in Fig. 9, the $I_{\mathrm{D} 1} / I_{\mathrm{G}}$ value was consistent with catalytic activity trend of semi-char with different conversion levels. This reveals that the catalytic reactivity of IWC on semi-char at different conversion levels is a positive relationship to the order degree of carbon structure of semi-char.

\section{Conclusions}

The desirable loading ratio of IWC at $1000{ }^{\circ} \mathrm{C}$ was $5 \mathrm{wt} \%$. The distribution of $\mathrm{Fe}$ catalyst on coal char was uneven and Fe catalyst was concentrated on the surface of some chars. The specific surface area of YCW gasified semi-char decreased significantly with the increase of gasification time. i.e., the specific surface area reduced from $381.981 \mathrm{~m}^{2} / \mathrm{g}(0 \mathrm{~min})$ to $191.724 \mathrm{~m}^{2} / \mathrm{g}$ (3 min), simultaneously, the number of micropores and mesopores decreased sharply at the late gasification stage. The carbon microcrystalline structure of YCW gasified semi-char was gradually destroyed with the increase of gasification time, and the microcrystalline structure of small size was gradually generated, resulting in the decreasing order degree of carbon microcrystalline structure. IWC can be adopted to catalyze YCW gasification which could provide theoretical guidance for industrial solid waste recycling.

Acknowledgements The present work was supported by the National Natural Science Foundation of China (21968024) and the Project of Key Research Plan of Ningxia (2019BCH01001). The authors also gratefully thank Professor Junzhuo Fang for his help in taking SEMEDS photos. 
Open Access This article is licensed under a Creative Commons Attribution 4.0 International License, which permits use, sharing, adaptation, distribution and reproduction in any medium or format, as long as you give appropriate credit to the original author(s) and the source, provide a link to the Creative Commons licence, and indicate if changes were made. The images or other third party material in this article are included in the article's Creative Commons licence, unless indicated otherwise in a credit line to the material. If material is not included in the article's Creative Commons licence and your intended use is not permitted by statutory regulation or exceeds the permitted use, you will need to obtain permission directly from the copyright holder. To view a copy of this licence, visit http://creativecommons. org/licenses/by/4.0/.

\section{References}

Bai Y, Lv P, Li F, Song X, Su W, Yu G (2019) Investigation into Ca/ $\mathrm{Na}$ compounds catalyzed coal pyrolysis and char gasification with steam. Energy Convers Manag 184:172-179

Chang G, Wu W, Shi P, Ma J, Guo Q (2020) A promising composite bimetallic catalyst for producing $\mathrm{CH}_{4}$-rich syngas from bitumite one-step gasification. Energy Convers Manag 205:1-9

Ding L, Zhou Z, Guo Q, Wang Y, Yu G (2015) In situ analysis and mechanism study of char-ash/slag transition in pulverized coal gasification. Energy Fuels 29:3532-3544

Fan C, Jin H, Shang F, Feng H, Sun J (2019) Study on the surface structure development of porous char particles in catalytic supercritical water gasification process. Fuel Process Technol 193:73-81

Gao M, Lv P, Yang Z, Bai Y, Li F, Xie K (2017) Effects of $\mathrm{Ca} / \mathrm{Na}$ compounds on coal gasification reactivity and char characteristics in $\mathrm{H}_{2} \mathrm{O} / \mathrm{CO}_{2}$ mixtures. Fuel 206:107-116

Gil MV, Riaza J, Álvarez L, Pevida C, Rubiera F (2015) Biomass devolatilization at high temperature under $\mathrm{N}_{2}$ and $\mathrm{CO}_{2}$ : char morphology and reactivity. Energy 91:655-662

Huo W, Zhou Z, Chen X, Dai Z, Yu G (2014) Study on $\mathrm{CO}_{2}$ gasification reactivity and physical characteristics of biomass, petroleum coke and coal chars. Bioresour Technol 159:143-149

Li X, Hayashi J, Li C (2006) FT-Raman spectroscopic study of the evolution of char structure during the pyrolysis of a Victorian brown coal. Fuel 85:1700-1707

Li C, Liu X, Zhou Z, Dai Z, Yang J, Wang F (2016) Effect of heat treatment on structure and gasification reactivity of petroleum coke. Int J Coal Sci Technol 3:53-61

Li N, Li Y, Zhou H, Liu Y, Song Y, Zhi K, He R, Yang K, Liu Q (2017) Direct production of high hydrogen syngas by steam gasification of Shengli lignite/chars: significant catalytic effect of calcium and its possible active intermediate complexes. Fuel 203:817-824

Li W, Wu S, Wu Y, Huang S, Gao J (2019) Gasification characteristics of biomass at a high-temperature steam atmosphere. Fuel Process Technol 194:1-9

Liu X, Xiong B, Huang X, Ding H, Zheng Y, Liu Z, Zheng C (2017) Effect of catalysts on char structural evolution during hydrogasification under high pressure. Fuel 188:474-482
Liu M, Bai J, Kong L, Bai Z, He C, Li W (2020) The correlation between coal char structure and reactivity at rapid heating condition in TGA and heating stage microscope. Fuel 260:1-10

Mosqueda A, Wei J, Medrano K, Gonzales H, Ding L, Yu G, Yoshikawa K (2019) Co-gasification reactivity and synergy of banana residue hydrochar and anthracite coal blends. Appl Energy 250:92-97

Qi X, Guo X, Xue L, Zheng C (2014) Effect of iron on Shenfu coal char structure and its influence on gasification reactivity. J Anal Appl Pyrolysis 110:401-407

Sheng C (2007) Char structure characterised by Raman spectroscopy and its correlations with combustion reactivity. Fuel 86:2316-2324

Smith MW, Dallmeyer I, Johnson TJ, Brauer CS, McEwen JS, Espinal JF, Garciaperez M (2016) Structural analysis of char by Raman spectroscopy: improving band assignments through computational calculations from first principles. Carbon 100:678-692

Tay HL, Kajitani S, Wang S, Li C (2014) A preliminary Raman spectroscopic perspective for the roles of catalysts during char gasification. Fuel 121:165-172

Wei J, Gong Y, Ding L, Yu J, Yu G (2018) Influence of biomass ash additive on reactivity characteristics and structure evolution of coal char- $\mathrm{CO}_{2}$ gasification. Energy Fuels 32:10428-10436

Wei J, Guo Q, Ding L, Gong Y, Yu J, Yu G (2019) Understanding the effect of different biomass ash additions on pyrolysis product distribution, char physicochemical characteristics, and char gasification reactivity of bituminous coal. Energy Fuels 33:3068-3076

Xu B, Cao Q, Kuang D, Gasem KAM, Adidharma H, Ding D, Fan M (2019) Kinetics and mechanism of $\mathrm{CO}_{2}$ gasification of coal catalyzed by $\mathrm{Na}_{2} \mathrm{CO}_{3}, \mathrm{FeCO}_{3}$ and $\mathrm{Na}_{2} \mathrm{CO}_{3}-\mathrm{FeCO}_{3}$. J Energy Inst. https://doi.org/10.1016/j.joei.2019.08.004

Yu J, Tian F, Chow M, McKenzie L, Li C (2006) Effect of iron on the gasification of Victorian brown coal with steam: enhancement of hydrogen production. Fuel 85:127-133

Yu G, Yu D, Liu F, Yu X, Han J, Wu J, Xu M (2019) Different catalytic action of ion-exchanged calcium in steam and $\mathrm{CO}_{2}$ gasification and its effects on the evolution of char structure and reactivity. Fuel 254:1-8

Zhang F, Xu D, Wang Y, Argyle MD, Fan M (2015) $\mathrm{CO}_{2}$ gasification of powder river basin coal catalyzed by a cost-effective and environmentally friendly iron catalyst. Appl Energy 145:295-305

Zhang F, Fan M, Huang X, Argyle MD, Zhang B, Towler B, Zhang Y (2017) Catalytic gasification of a powder river basin coal with $\mathrm{CO}_{2}$ and $\mathrm{H}_{2} \mathrm{O}$ mixtures. Fuel Process Technol 161:145-154

Zhang X, Song X, Su W, Wei J, Bai Y, Yu G (2019) In-situ study on gasification reaction characteristics of Ningdong coal chars with $\mathrm{CO}_{2}$. J Fuel Chem Technol 47:385-392

Zheng P, Wang Y, Liu C, Guo W, Bai L, Hu X, Lin X (2019) Effects of inherent alkali and alkaline earth metals on nitrogen transformation during steam gasification of Shengli lignite. Int J Coal Sci Technol 6:197-206 